
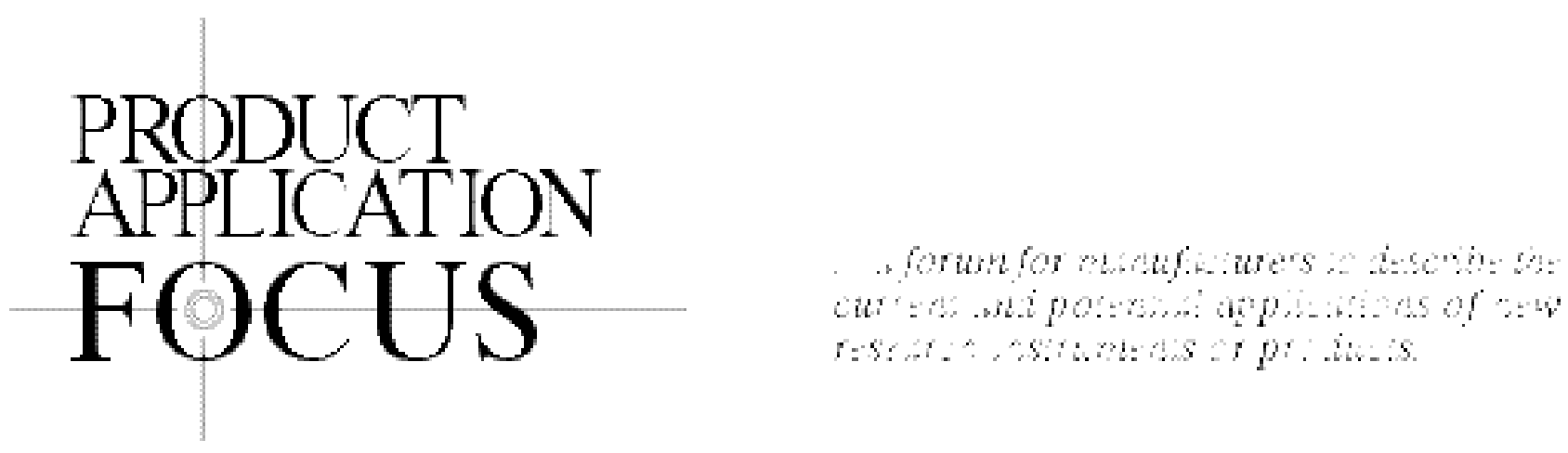

\title{
Detection and Identification of Virulence Factors in Yersinia pestis Using SELDI ProteinChip ${ }^{\circledR}$ System
}

\author{
Vanitha Thulasiraman, Sandra L. McCutchen-Maloney1, Vladimir L. Motin', \\ and Emilio Garcia ${ }^{1}$ \\ Ciphergen Biosystems, Fremont, CA, ${ }^{1}$ Lawrence Livermore National Laboratory, \\ Livermore, CA, USA
}

BioTechniques 30:428-432 (February 2001)

\begin{abstract}
A rapid method for the detection, purification, and identification of proteins in bacterial extracts was developed using surface enhanced laser desorption/ionization (SELDI) ProteinChip ${ }^{\circledR}$ technology. The effectiveness of this technique for monitoring the expression and identification of temperature-and calcium-regulated virulence factors of Yersinia pestis, the bacterium that causes human plague, is demonstrated. Y. pestis infection of its mammalian host is thought to be accompanied by rapid up-regulation of a number of genes following a shift from $26^{\circ} \mathrm{C}$ (the temperature of the flea vector) to $37^{\circ} \mathrm{C}$ (the temperature of the mammalian host). To model this process, Y.

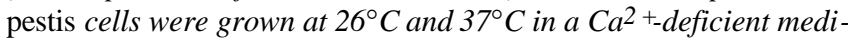
um. Through an initial protein profiling of the crude bacterial extract on strong anion exchange and copper affinity, ProteinChip arrays detected five proteins that were up-regulated and three proteins that were down-regulated at $37^{\circ} \mathrm{C}$. Two of the proteins predominately expressed at $37^{\circ} \mathrm{C}$ were semi-purified in less than two days. The two proteins were identified as catalase-peroxidase and Antigen 4. Aside from its speed, a salient feature of the SELDI technique is the microgram amounts of crude sample required for analysis.
\end{abstract}

\section{INTRODUCTION}

The explosive progress over the past decade in the fields of protein science, bioinformatics, and genomics has resulted in an increased demand for the development of high-throughput technology that allows for the detection, purification, and identification of proteins at high speed and with high sensitivity. With the wealth of information coming from completed genome projects, the next logical step is proteomic-scale protein analysis. For example, analysis and correlation of mRNA expression with protein expression within an organism require biochemical analysis of thousands of genes and proteins. In the present work, we show that surface enhanced laser desorption/ionization (SELDI) ProteinChip ${ }^{\circledR}$ array technology $(6,9)$ (Ciphergen Biosystems, Palo Alto, CA, USA) is uniquely suited for these kinds of studies, as exemplified by the analysis of several temperature-dependent Yersinia pestis virulence factors.

$Y$. pestis, the bacterium that causes sylvatic and human plague, was used as a model organism to demonstrate the feasibility of the SELDI technique to differentiate proteins expressed under two different growth conditions. Plague is primarily a disease that affects rodents and is transmitted by their associated fleas to humans. During the bacterial residency in the flea, a large number of the proteins involved in mam malian infection are not expressed due to the lower temperature encountered in that host. Expression of virulence factors takes place shortly after $Y$. pestis cells are passed from fleas to 
the unique and higher-temperature environment of the mam malian host (10). Temporal induction of selected virulence genes during temperature shift has been previously studied by the direct measurement of the levels of mRNA during this transition (5).

In the current study, we chose the cultivation of yersiniae cells in a $\mathrm{Ca}^{2+}$-deficient media that is associated with the upregulation of plasmid- and chromosome-encoded virulence factors upon temperature shift from $26^{\circ} \mathrm{C}$ (temperature encountered in the flea vector) to $37^{\circ} \mathrm{C}$ (temperature of the mammalian host) (8). Dissecting this mechanism of pathogen adaptation is thus an important element in understanding this process. We demonstrate here that SELDI can be used to monitor protein expression levels at the two temperatures with exquisite sensitivity, allowing facile correlation to mRNA expression levels. This approach will lead to a better understanding of the changes occurring during the temperature induction of virulence genes of $Y$. pestis.

\section{MATERIALS AND METHODS}

\section{Bacterial Lysate Preparation}

A non-pigmented isolate of $Y$. pestis carrying all three virulence plasmids (pCP1, pMT1, and pPCP1; substrain D27), KIM10 was used to prepare protein lysate samples (4). Cells were grown in $\mathrm{Ca}^{2+}$-deficient WCS, $\mathrm{pH} 6.8$, medium to achieve a low-calcium response as described previously (3). Briefly, yersiniae were grown at $26^{\circ} \mathrm{C}$ to an absorbance of 0.25 at $620 \mathrm{~nm}\left(A_{620}\right)$, at which time half of the culture was shifted to $37^{\circ} \mathrm{C}$. Both the cells remaining at $26^{\circ} \mathrm{C}$ and those shifted to $37^{\circ} \mathrm{C}$ were harvested at $6 \mathrm{~h}$ after the temperature shift (at an $A_{620}$ of 1.0-1.2). Cell pellets obtained from 120 $\mathrm{mL}$ culture were suspended in $5 \mathrm{~mL} 20 \mathrm{mM}$ HEPES, pH 7.4, $50 \mathrm{mM} \mathrm{NaCl}$, and disrupted using a French Press (SLM Instruments, Urbana, IL, USA) at 750 psi. The cell debris was removed by centrifugation $\left(20000 \times g\right.$ for $20 \mathrm{~min}$ at $\left.4^{\circ} \mathrm{C}\right)$, and the supernatant was stored in aliquots at $-70^{\circ} \mathrm{C}$. Protein concentration was determined using the BCA kit (Pierce Chemical, Rockford, IL, USA) and adjusted to a concentration of 2 $\mathrm{mg} / \mathrm{mL}$ before SELDI analysis.

\section{Processing and Analysis of ProteinChip Arrays}

The SELDI analysis was performed using $10 \mu \mathrm{g}$ crude cytosol extract of $Y$. pestis grown at $26^{\circ} \mathrm{C}$ and $37^{\circ} \mathrm{C}$, respective1y. A strong anion exchange ProteinChip array (SAX-2; Ciphergen Biosystems) was employed to capture negatively charged proteins, and an immobilized copper affinity array (IMAC-Cu${ }^{++}$; Ciphergen Biosystems) was used to capture proteins with affinity for copper to select for a specific subset of proteins from the $Y$. pestis crude extracts. Captured proteins were directly detected using a PBSII ProteinChip Array reader (Ciphergen Biosystems), a laser desorption/ionization time-of-flight mass spectrometer.

Before loading the cell lysate, the SAX-2 array was equilibrated two times with $5 \mu \mathrm{L} 20 \mathrm{mM}$ HEPES, pH 7.4 (5 min each). After removing the equilibration buffer, $5 \mu \mathrm{L}$ cell lysate was added and incubated for 15 min on a rocker. Cell lysate was removed, and the surface was washed three times with the equilibration buffer ( 5 min each). A quick final rinse with water was performed. The surface was allowed to dry, followed by two additions of $0.4 \mu \mathrm{L}$ saturated sinapinic acid (SPA; Ciphergen Biosystems) in 50\% acetonitrile and $0.5 \%$ trifluoroacetic acid (TFA). Captured proteins were detected using the ProteinChip Reader.

The same procedure was followed for the IMAC-Cu${ }^{++}$array with the following modifications. The surface was first loaded with $5 \mu \mathrm{L} 50 \mathrm{mM}$ copper sulfate two times for $5 \mathrm{~min}$, followed by a quick rinse with water to remove the unbound copper. The surface was then equilibrated two times with 5 $\mu \mathrm{L}$ PBS (5 min each). For the NP-2 chips (Normal Phase array; Ciphergen Biosystems), samples were applied directly to the surface.

\section{Tryptic Digestion and Peptide Mapping}

The two bands of interest (up-regulated proteins) were excised from the SDS-PAGE gel. An in-gel digest with $1 \mathrm{pmol}$ trypsin was performed (11). The tryptic digestion was done overnight at $37^{\circ} \mathrm{C}$ in a reaction volume of $30 \mu \mathrm{L} 50 \mathrm{mM}$ ammonium bicarbonate buffer, $\mathrm{pH}$ 8.0. Subsequently, $2 \mu \mathrm{L}$ of the digestion mixture were analyzed on NP-2. Alpha-cyano4-hyroxy cinnamic acid (Ciphergen Biosystems) was used to detect peptides generated in the tryptic digest. The masses of the tryptic digested peptides were measured on a PBSII system that had been calibrated using internal standards. Molecular weights of the peptides were used for protein identification using the ProFound Database, with a mass tolerance of 1 Da and a maximum missed cut of 1 .

\section{RESULTS AND DISCUSSION}

Differential expression of proteins in $Y$. pestis grown at $37^{\circ} \mathrm{C}$ and $26^{\circ} \mathrm{C}$ was examined by SELDI mass spectrometry

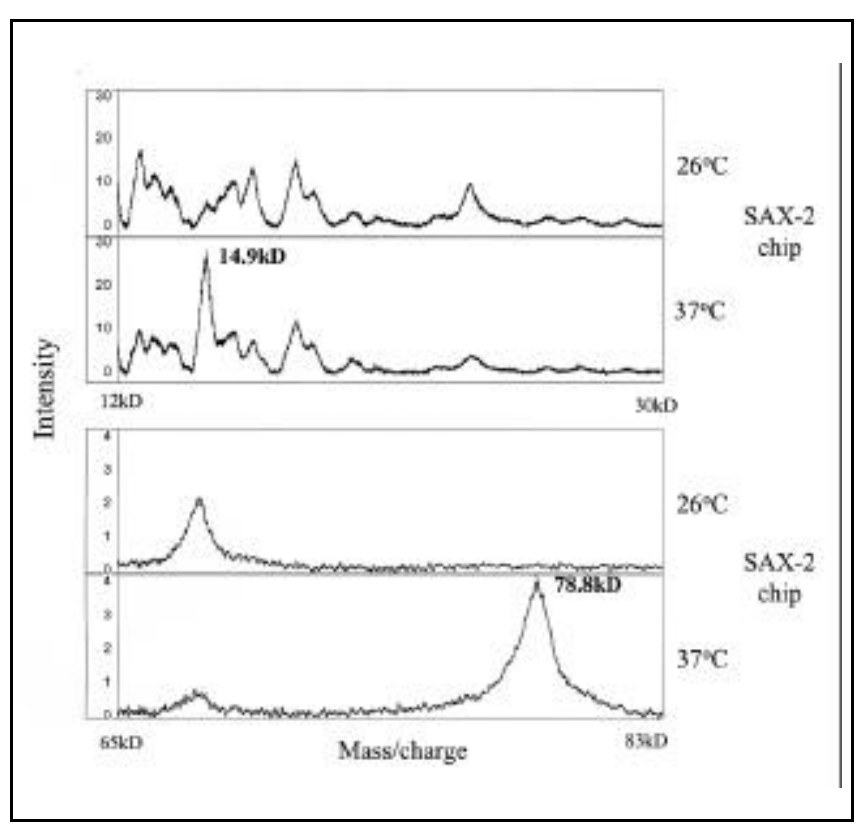

Figure 1. SELDI capture of proteins from bacterial cell lysate onto SAX2 ProteinChip array. Top and bottom panel are different molecular weight regions of the same spectra. Ten micrograms of crude cytosolic extracts of $Y$. pestis grown at $26^{\circ} \mathrm{C}$ versus $37^{\circ} \mathrm{C}$ were analyzed on SAX-2 chip. The 14.9and $78.8-\mathrm{kDa}$ proteins were expressed only at $37^{\circ} \mathrm{C}$. The experiment was repeated five times. 


\section{0 ul bacterial lysate $(15 \mathrm{mg} / \mathrm{ml})$}

(adjusted to $0.5 \mathrm{M} \mathrm{NaCl}, 0.1 \% \mathrm{TX}-100$ )

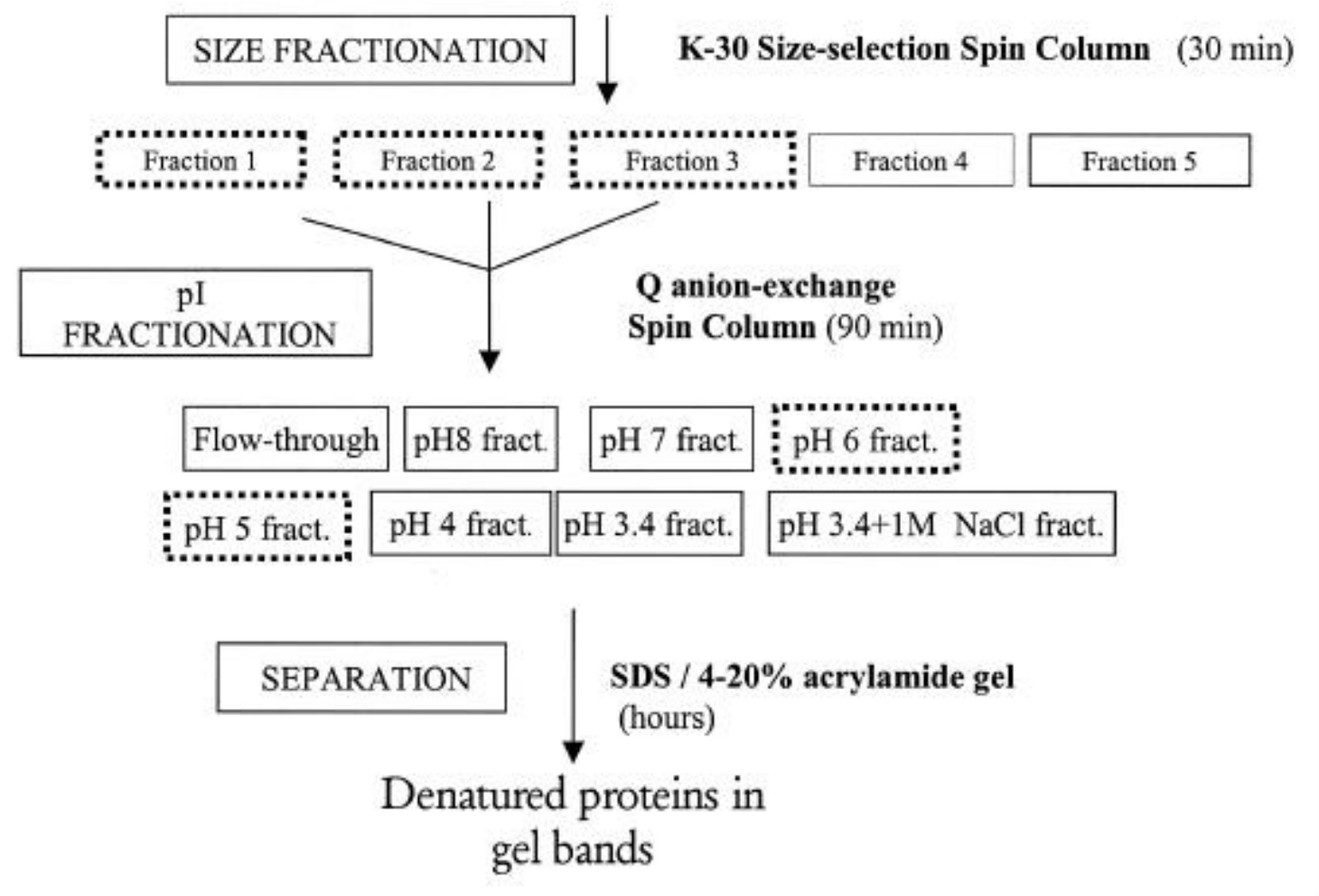

Figure 2. Partial purification scheme (developed at Ciphergen Biosystems, by T. Pham) of the two temperature-inducible proteins using spin columns.

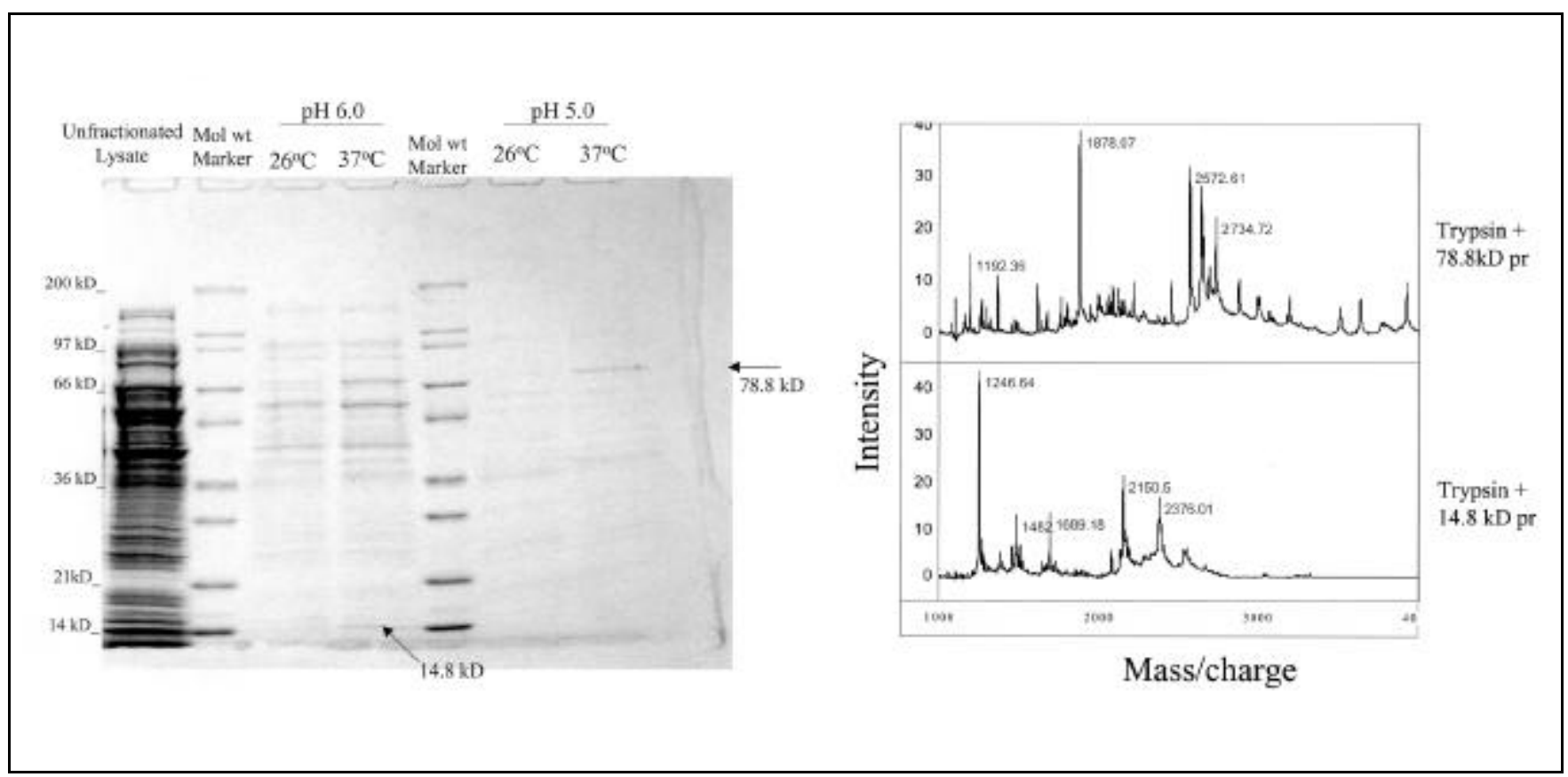

Figure 3. Final purification for tryptic mapping. (A) Separation on SDS-PAGE gel for tryptic digestion. $140 \mu \mathrm{L}$ of $\mathrm{pH} 6.0$ and $\mathrm{pH} 5.0$ fractions of the anion exchange column from both $26^{\circ} \mathrm{C}$ and $37^{\circ} \mathrm{C}$ lysate were loaded on the gel. The gel was stained with Coomassie ${ }^{\circledR}$ Blue. (B) Analysis of the peptides generated by tryptic digestion on SELDI time-of-flight mass spectrometry. Two microliters of the $30 \mu \mathrm{L}$ trypsin digestion mixture were analyzed on an NP-2 array. 
Table 1. Identification of (A) the 78.8-kDa Protein and (B) the 14.9-kDa Protein by Comparison of Peptide Maps to the NCBI Protein Database

\begin{tabular}{|lllc|}
\hline A. & & & \\
Rank & Probability & Protein Description & MW $(\mathrm{kDa})$ \\
\hline 1 & $1.0 \mathrm{e}+00$ & Catalase/peroxidase-Yersinia pestis & 81 \\
2 & $3.5 \mathrm{e}-31$ & Transferrin-binding protein2-Haemophilus influenza & 70 \\
B. & & & \\
Rank & Probability & Protein Description & $\mathrm{MW}(\mathrm{kDa})$ \\
\hline 1 & $5.0 \mathrm{e}-01$ & Antigen 4 (adhesin)-Yersinia pestis & 15 \\
2 & $6.9 \mathrm{e}-04$ & E. coli hypothetical protein & 16 \\
\hline
\end{tabular}

using SAX-2 and IMAC-Cu ${ }^{++}$(figure not shown) ProteinChip arrays. Specifically, $10 \mu \mathrm{g}$ total protein lysate were used to capture a subset of proteins based on the affinity of the bacterial proteins for the two ProteinChip surfaces used. Captured proteins were then detected directly from the ProteinChip surface by time-of-flight mass spectrometry using the SELDI system. This process was completed in less than 1 $\mathrm{h}$ by analyzing multiple samples in parallel on the same ProteinChip array. Two proteins of mass 14.9 and $78.8 \mathrm{kDa}$ in samples from bacteria grown at $37^{\circ} \mathrm{C}$ for $6 \mathrm{~h}$ (Figure 1), which were not seen in samples from bacteria grown at $26^{\circ} \mathrm{C}$, bound to the SAX-2 ProteinChip. Both proteins bound at $\mathrm{pH}$
7.4, suggesting that each had a pI less than 7.4. In addition, the $78.8-\mathrm{kDa}$ protein also bound to the IMAC-Cu${ }^{++}$ProteinChip, suggesting the presence of at least one free histidine imidazole group on the surface. In contrast, the 14.9-kDa protein bound to the SAX-2 ProteinChip but not to the IMAC$\mathrm{Cu}^{++}$ProteinChip, suggesting the absence of a free metal binding motif. The experiments were repeated five times, and in all repeats the two proteins were detected only in samples from bacteria grown at $37^{\circ} \mathrm{C}$.

To identify the 78.8- and 14.9-kDa proteins, a partial purification scheme was devised (Figure 2). Since both proteins apparently had a pI lower than 7.4 while differing in size, 600 
$\mu \mathrm{g}$ total bacterial lysate were first separated by molecular weight using a K30 size selection spin column (Ciphergen Biosystems). Five $30-\mu \mathrm{L}$ fractions were collected, of which 1 $\mu \mathrm{L}$ each fraction was spotted on an NP-2 ProteinChip to monitor the elution of the $78.8-\mathrm{kDa}$ protein (data not shown). The first three fractions, which contained the protein, were pooled and passed over an anion exchange spin column (Ciphergen Biosystems). Using a step $\mathrm{pH}$ gradient from 9.0 to 3.4, the proteins were further separated on the basis of their pI. Eight 150- $\mu \mathrm{L}$ fractions were collected, of which 1-5 $\mu \mathrm{L}$ each fraction were spotted on an NP-2 ProteinChip to monitor the elution of the $78.8-\mathrm{kDa}$ protein (data not shown). A $140-\mu \mathrm{L}$ aliquot of fractions that contained the $78.8-\mathrm{kDa}$ protein was concentrated and run on a 4\%-20\% SDS-PAGE gradient gel (Figure 3A). Surprisingly, a fraction of the 14.9-kDa protein eluted in the high molecular weight fraction from the K30 size exclusion column as well, suggesting that it might be a component of a larger complex. Further purification of the 14.9-kDa protein on the anion exchange column revealed that the protein eluted at pH 6.0 (Figure 3A).

After partial fractionation of both proteins, which largely eliminated other proteins that comigrate on the SDS-PAGE gel, the protein bands were cut from the gel for subsequent trypsin digestion. Following tryptic digestion of the proteins, the peptide fragments were analyzed by SELDI, which revealed 47 peptides for the 78.8-kDa protein. A search of the NCBI protein Database by ProFound was performed that included all kingdoms and proteins with a mass range from 10 to $100 \mathrm{kDa}$. Out of these 47 peptides, 35 matched with the catalase/peroxidase KatY protein (also known as Antigen 5 or p70) of $Y$. pestis (Table 1A). The remaining unmatched peptides could be from contaminants such as keratin and trypsin. Several additional lines of evidence support the notion that this protein is indeed KatY. First, expression of KatY is known to be induced at $37^{\circ} \mathrm{C}$. Second, the enzyme is expressed as an 81.4-kDa protein containing a leader signal sequence of $2.6 \mathrm{kDa}(2,4)$, which upon processing leaves a 78.8-kDa protein, matching the molecular mass determined by SELDI. Third, the predicted pI of KatY is 6.4, explaining its elution off the anion exchange spin column at $\mathrm{pH} 6.0$ and its affinity for the SAX-2 ProteinChip at neutral $\mathrm{pH}$. Finally, amino acids 96-109 and 255-268 are active site motifs encoding proximal and distal histidine imidazoles, which presumably facilitated binding to the IMAC-Cu++ ProteinChip.

Tryptic digestion of the 14.9-kDa protein generated eight peptides (Figure 3B), three of which matched the Antigen 4 protein (also known as pH 6 antigen) of $Y$. pestis (Table 1B). Antigen 4, like KatY, is known to be induced at $37^{\circ} \mathrm{C}$ (1) and in conditions of low calcium (8). In addition, Antigen 4 possesses a fibrillar structure required for full virulence (7), which may explain its elution in the higher molecular weight fraction on the K30 size exclusion column under the native conditions used in these experiments.

As described here, two virulence factors, KatY and Antigen 4, of $Y$. pestis were identified using the SELDI ProteinChip technology by measuring protein expression levels at $37^{\circ} \mathrm{C}$ and $26^{\circ} \mathrm{C}$. In support of the findings reported, expression of both genes encoding for KatY and Antigen 4 was also observed at the described conditions using mRNA analysis by dot-blot hybridization (5). Importantly, as we have shown, the entire process of profiling protein expression patterns to the identification of a specific protein can be executed in only three days.

\section{ACKNOWLEDGMENTS}

The portion of this work undertaken at Lawrence Livermore National Laboratory was performed under the auspices of the U.S. Department of Energy under contract no. W-7405ENG-48.

\section{REFERENCES}

1.Bichowsky-Slomnicki, L. and S. Ben-Efraim. 1963. Biological activities in extracts of Pasteurella pestis and their relation to the " $\mathrm{pH} 6$ antigen". J. Bacteriol. 86:101-111.

2.Crumpton, M.Y. and D.A.L. Davies. 1956. An antigenic analysis of Pasteurella pestis by diffusion of antigens and antibodies in agar. Proc. R. Soc. Lond. Ser.B 145:109-134.

3.Fowler, J.M. and R.R. Brubaker. 1994. Physiological basis of the low calcium response in Yersinia pestis. Infect. Immun. 62:5234-5241.

4.Garcia, E., Y.A. Nedialkov, J. Elliott, V.L. Motin, and R.R. Brubaker. 1999. Molecular characterization of KatY (antigen 5), a thermoregulated chromosomally encoded catalase-peroxidase of Yersinia pestis. J. Bacteriol. 181:3114-3122.

5.Garcia, E., Y.A. Nedialkov, J. Elliott, V.L. Motin, and R.R. Brubaker. 1999. Molecular characterization of KatY a thermoregulated catalase-peroxidase of Yersinia pestis. Abstr. B/D-300, p.88. In Abstracts of the 99th General Meeting of the American Society for Microbiology. American Society for Microbiology, Washington, D.C.

6.Hutchen, T.W. and T.-T. Yip. 1993. New desorption strategies for the mass spectrometric analysis of macromolecules. Rapid Commun. Mass Spectrom. 7:576-580.

7. Lindler, L.E., M.S. Klempner, and S.C. Straley. 1990. Yersinia pestis pH 6 antigen: genetic, biochemical, and virulence characterization of a protein involved in the pathogenesis of bubonic plague. Infect. Immun. 58:2569-2577.

8.Mehigh, R.J. and R.R. Brubaker. 1993. Major stable peptides of Yersinia pestis synthesized during the low-calcium response. Infect. Im mun. 61:13-22.

9.Merchant, M. and S.R. Weinberger. 2000. Recent advancement in surface enhanced laser desorption/ionization-time of flight-mass spectrometry. Electrophoresis $21: 1164-1167$.

10.Perry, R.D. and J.D. Fetherston. 1997. Yersinia pestis-ethiologic agent of plague. Clin. Microbiol. Rev. 10:35-66.

11.Stone, K.L. and K.R. Williams. 1996. Enzymatic digestion of proteins in solution and in SDS polyacrylamide gels, p. 415-425. In J.M. Walker (Ed.), The Protein Protocols Handbook. Humana Press, Totowa, NJ.

Address correspondence to Dr. Vanitha Thulasiraman, Ciphergen Biosystems Inc., 6611 Dumbarton Circle, Fremont, CA, USA. e-mail: vanitha@ciphergen.com 